International Journal of Engineering \& Technology, $7(2.33)(2018) 384-388$
International Journal of Engineering \& Technology
Website: $w w w . s c i e n c e p u b c o . c o m / i n d e x . p h p / I J E T$
Research paper

\title{
Reduction method of residual voltage by connecting lead length of surge protection device
}

\author{
Young-Dal Kim ${ }^{1}$, Young-Chan Kim ${ }^{1}$, Yun-Mi Jeong ${ }^{1}$, Dae-Dong Lee ${ }^{1 *}$ \\ ${ }^{1}$ Department of Electrical Engineering, Hanbat National University, Daejeon, 34158, Korea \\ *Corresponding author E-mail: ldd77@ hanbat.ac.kr
}

\begin{abstract}
Background/Objectives: In order to minimize the damage and malfunction of the equipment and system from various surges, we studied the method of reducing the residual voltage according to the lead wire length of the surge protector.

Methods/Statistical analysis: In buildings, SPD installation space is insufficient or narrow, resulting in longer lead wire of SPD, and SPD protection performance is decreased due to increase of voltage protection level and residual voltage. In this study, the voltage protection level and the residual voltage of the conventional SPD model and the proposed SPD model are analyzed according to the change of the connecting conductor length from 0.5 to $100 \mathrm{~m}$.

Findings: In the case of the conventional SPD model, the protection level of the SPD is excellent by measuring the voltage protection level at $1,410 \mathrm{~V}$ even if the lead wire length of the connecting conductor is changed to $10 \mathrm{~m}$, but when it exceeds $10 \mathrm{~m}$, the protection performance and the protection cooperation are reduced. On the other hand, in the case of the proposed SPD model, the voltage protection level was measured to be $50 \mathrm{~V}$ or less even if the lead wire length of the connecting conductor was changed to $100 \mathrm{~m}$. Therefore, it is considered that SPD protection performance and protection cooperation are excellent.

Improvements/Applications: The design technique of SPD obtained through this study will help to select the optimal installation site and reduce the budget.
\end{abstract}

Keywords: Surge Protection Circuit; Surge Protective Device (SPD); Protection Coordination; Residual Voltage; Voltage Protection Level.

\section{Introduction}

Grounding is the most basic stabilizing method for electrical equipment. Inadequately grounded equipment can cause electric shock while various surges can cause equipment and system damage and malfunction [1-3]. To solve this problem, lightning arrester (LA) are used in the transmission and distribution field, and increasingly stringent regulations are being enforced to install surge protective device (SPD) in general buildings with voltages lower than $1,000 \mathrm{~V}$ [4-6].Various surges, such as lightning surges and the switching surges generated from electrical equipment, have a fast rise time of $1.2 \mu \mathrm{s}$ and large currents rising up to scores of kA's. Surge protectors have a fast response characteristic of $1 \mu \mathrm{s}$ and hundreds of $\mathrm{m} \Omega$ of low impedance. The surge protectors in SPDs that are used in the power circuit include built-in devices such as zener diodes, avalanche diode, varistor and gas discharge tubes. The resistance and reactance characteristics of the surge protector vary according to the length of the conductor connected to the SPD [7]. The longer the conductor connected to the SPD is, the higher the impedance of the conductor due to the surge current, and thus the higher the voltage protection level and the residual voltage as well [8]. In particular, the residual voltage due to the peak value of the voltage that appears between the terminals of the SPD triggered by the passage of the discharged current deteriorates the transient voltage protection performance of the SPD when the connection conductor becomes longer due to the vibration phenomenon of surge [9-12].Therefore, it is indicated in KS C IEC 60364-5-3-53 that the conductor connected to the SPD should be less than $0.5 \mathrm{~m}$ long for optimum transient voltage protection. In the buildings that had been built before the installation of the SPD became mandatory, however, the space available for installing the SPD is often insufficient or narrow, thereby making it impossible to make the conductor connected to the SPD less than $0.5 \mathrm{~m}$ long. Therefore, there is an urgent need to develop an SPD with an excellent protection performance, and to select an optimum installation position for it [13].In this study, the lead wire lengths of the conductors connected to the SPD were changed to $0.5,3,5,10,20,50$, and $100 \mathrm{~m}$ for the conventional and proposed SPD models, respectively, for the analysis of the voltage protection level and residual voltage, and to verify the protection coordination.

\section{Experiment and methods}

\subsection{Surge protection circuit}

A surge protector consisting of one or more nonlinear devices is installed in a $50 / 60 \mathrm{~Hz}$ power circuit and in an equipment with less than $1,000 \mathrm{Vrms}$ to protect them from direct or indirect effects, such as lighting or other transient voltages. The surge protection circuit of the conventional SPD model, which is constructed as shown in Figure 1, has a voltage-limiting structure that includes MOVs (metal oxide varistors) between L-N, L-G, and N-G, respectively. With regard to the protection operation triggered by lightning and transient voltage, the surge introduced between $\mathrm{L}$ and $\mathrm{G}$ is blocked by MOV1, that introduced between N and G is blocked by MOV2, and that introduced between $\mathrm{L}$ and $\mathrm{N}$ is blocked by MOV3. In addition, TF1 and TF2 are disconnectors or fuses installed as a stabi- 
lizing device to prevent short-circuit accidents in the case of an insulation breakdown or an anomaly related to the service life of the SPD. The surge protection circuit of the proposed SPD model is constructed as shown in Figure 2.It is a two-port surge protector, in which the input and output are separated by combining MOV3 between $\mathrm{L}$ and N, MOV2 between L and G, and MOV3 between $\mathrm{N}$ and $\mathrm{G}$, along with SP modules 1, 2, and 3, respectively.

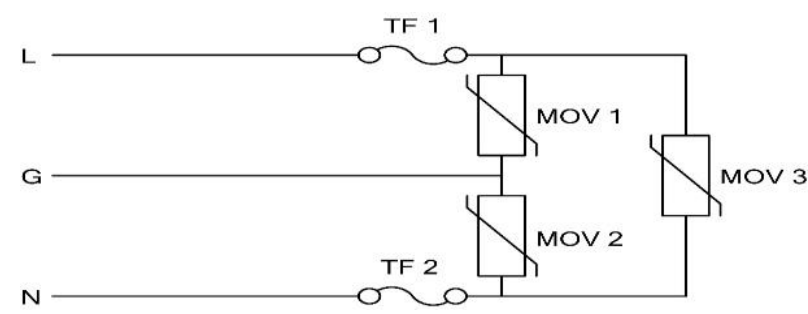

Fig. 1: Circuit Diagram of Conventional SPD Model.

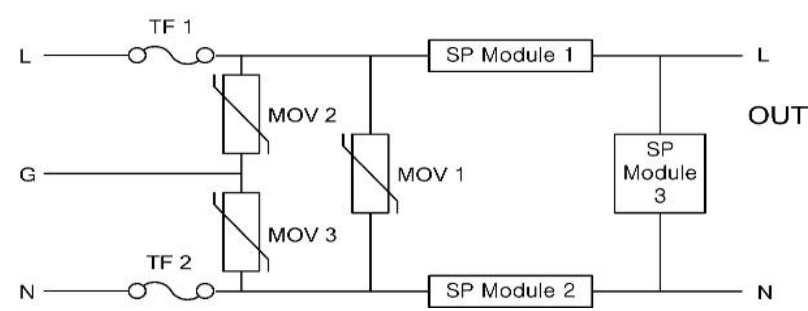

Fig. 2: Circuit Diagram of Proposed SPD Model.

\subsection{Experimental system configuration}

Figure 3 shows the configuration of the experimental system. Figure 3(a) shows the experimental system configuration of the conventional SPD model, and Figure 3(b) shows the experimental system configuration of the proposed SPD model. $1.2 / 50 \mu \mathrm{s}, 6 \mathrm{kV}$ and $8 / 20 \mu \mathrm{s}, 3 \mathrm{kV}$ voltages were applied to the inlet points of the conventional and proposed SPD models using a surge generator (DY904C) according to the standard of KS C IEC61000-4-5, to apply the surge voltage and current. Moreover, the voltage protection level and the residual voltage were measured using an oscilloscope (LeCroy, LC564A) while changing the lead wire length of the connecting conductor to $0.5,3,5,10,20,50$, and $100 \mathrm{~m}$, respectively.

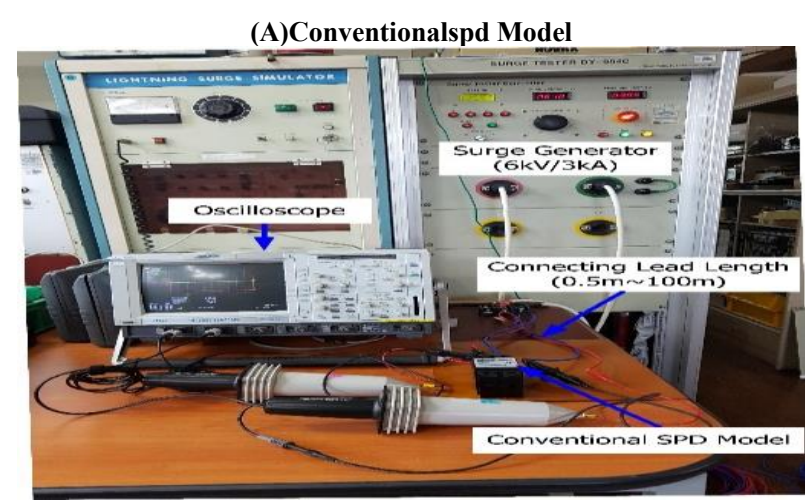

(B) Proposed SPD Model

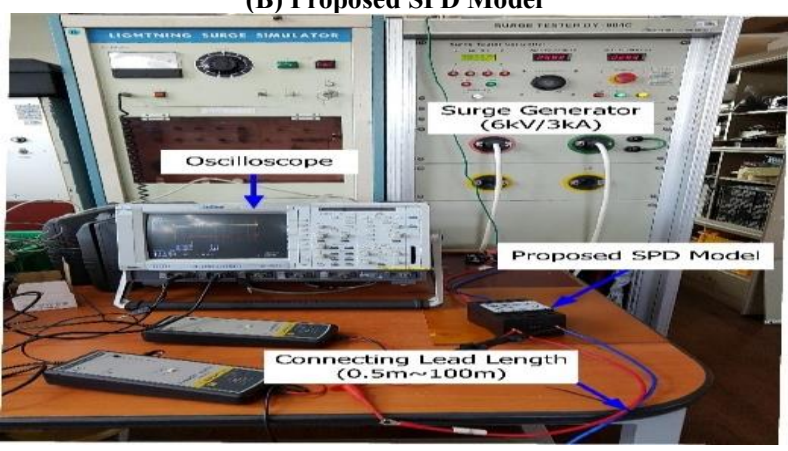

Fig. 3: Composition of Experiment System.

\section{Results and discussion}

\subsection{Experiment results of the conventional SPD model}

Figure 4 shows the experiment results of the conventional SPD model, with Figure 4(a) 4(g) showing the voltage protection levels when the lead wire length of the connecting conductor was changed from 0.5 to $100 \mathrm{~m}$. As shown in Figure 4(a) and 4(b), the voltage protection levels were measured to be 1,060 and $1,130 \mathrm{~V}$, respectively, when the lengths of the connecting conductors were changed to 0.5 and $3 \mathrm{~m}$, respectively. As shown in Figure 4(c), the voltage protection level was measured to be $1,190 \mathrm{~V}$ when the length of the connecting conductor was changed to $5 \mathrm{~m}$. Compared with the connecting conductors measuring 0.5 and $3 \mathrm{~m}$, respectively, the voltage protection level did not increase significantly, and it can be confirmed in Figure 4(d) and 4(e) that the voltage protection levels were measured to be 1,410 and $1,780 \mathrm{~V}$ while the voltage protection levels increased gradually when the length of the connecting conductor was changed to 10 and $20 \mathrm{~m}$, respectively. Finally, as shown in Figure 4(f) and 4(g), the voltage protection levels were measured to be 1,970 and $2,060 \mathrm{~V}$, respectively when the length of the connecting conductor was changed to 50 and $100 \mathrm{~m}$, respectively and it can be confirmed that the residual voltage is greatly increased. In particular, the vibration phenomenon increased and the protection performance of SPD is expected to decrease due to the high frequency noise when the connecting conductor was longer than $50 \mathrm{~m}$.

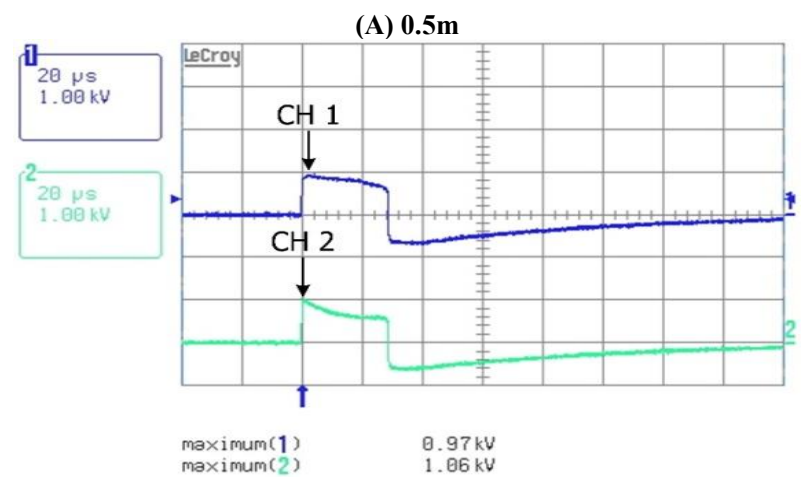

(B) $3 \mathrm{~m}$

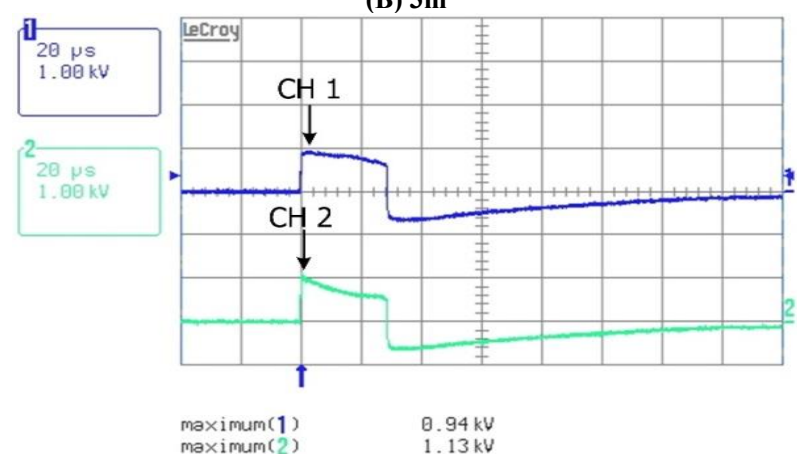

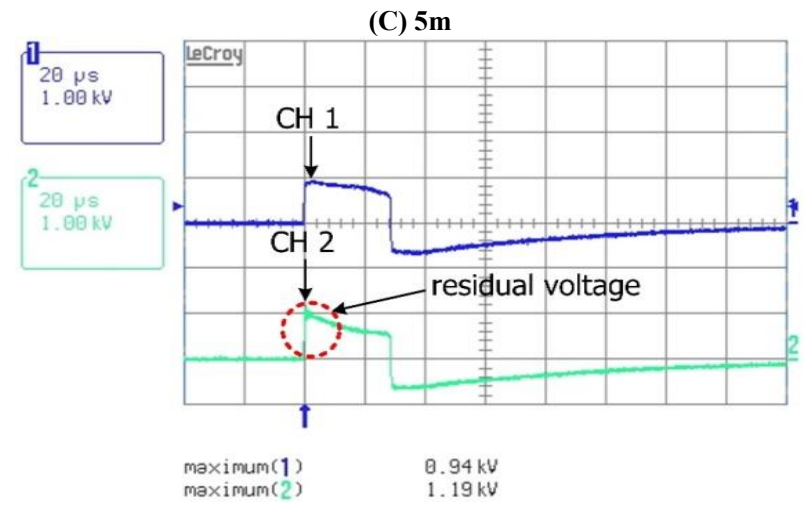


(D) $10 \mathrm{~m}$

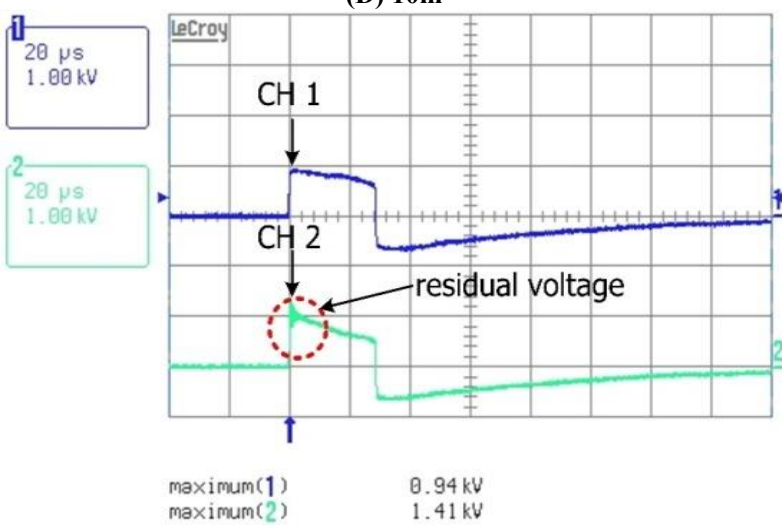

(E) $20 \mathrm{~m}$
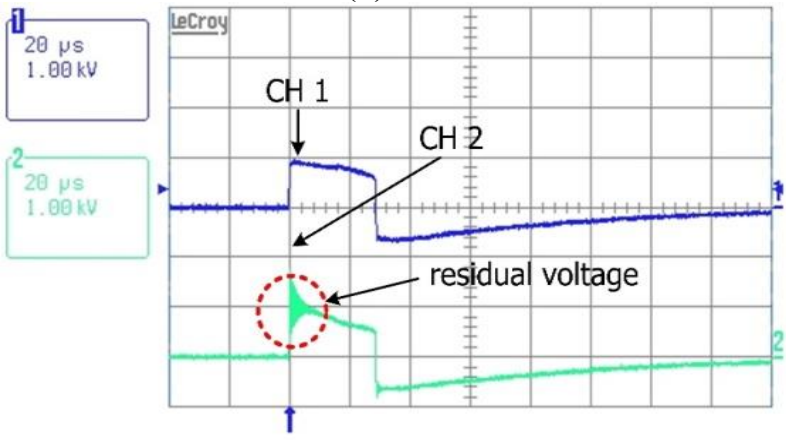

$\begin{array}{ll}\operatorname{maximum}(1) & 0.97 \mathrm{kV} \\ \operatorname{maximum}(2) & 1.78 \mathrm{kV}\end{array}$

(F) $50 \mathrm{~m}$
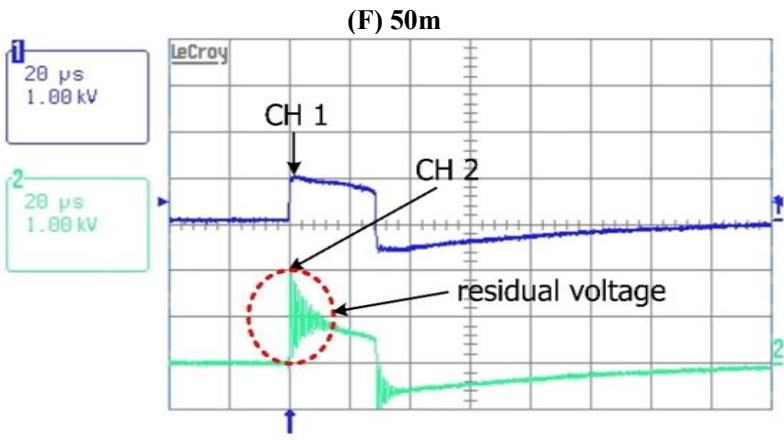

$\begin{array}{ll}\operatorname{maximum}(1) & 0.96 \mathrm{kV} \\ \operatorname{maximum}(2) \downarrow & 1.97 \mathrm{kV}\end{array}$

(G) $100 \mathrm{~m}$
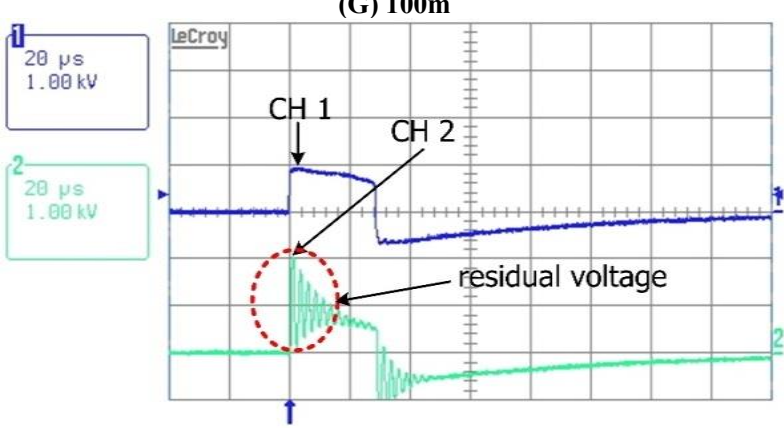

maximum(1)

maximum (2) $\downarrow$

$0.94 \mathrm{kV}$

$2.06 \mathrm{kV}$

Fig. 4: Experiment Results of Conventional SPD Model.

\subsection{Experiment results of the proposed SPD model}

Figure 5 shows the experiment results of the proposed SPD model. Figure 5 (a) $\sim 5$ (g) show the voltage protection levels when the lead wire length of the connecting conductor was changed from 0.5 to $100 \mathrm{~m}$. As shown in Figure 5(a) and 5 (b), the voltage protection levels were measured to be $28.1 \mathrm{~V}$ when the length of the connecting conductor was changed to 0.5 and $3 \mathrm{~m}$, respectively. It was also confirmed that there was almost no difference from the voltage protection level measured at the entry point of the SPD.As shown in Figure 5 (c), the voltage protection level was measured to be $45.3 \mathrm{~V}$ when the length of the connecting conductor was changed to $5 \mathrm{~m}$, confirming that the voltage protection levels increased very slightly compared to when the length of the connecting conductor was 0.5 and $3 \mathrm{~m}$, respectively. As shown in Figure 5 (d), the voltage protection level was measured to be $31.3 \mathrm{~V}$ when the length of the connecting conductor was changed to $10 \mathrm{~m}$. The voltage protection level was lower compared to when the length of the connecting conductor was $5 \mathrm{~m}$, but it was judged to be within the measurement error margin. As shown in Figure 5(e), the voltage protection level was measured to be $50.0 \mathrm{~V}$ when the length of the connecting conductor was changed to $20 \mathrm{~m}$. The voltage protection levels were measured to be 48.4 and $39.1 \mathrm{~V}$, respectively, when the length of the connecting conductor was changed to 50 and $100 \mathrm{~m}$, as shown in Figure 5(f) and 5(g). The voltage protection level when the length of the connecting conductor was changed to $100 \mathrm{~m}$ was lower than when the length of the connecting conductor was $50 \mathrm{~m}$, but it was considered that the peak value decreases due to the increase of the low frequency vibration while absorbing the high frequency pulse due to the increase of the line capacity in the frequency pattern.

(A) $0.5 \mathrm{~m}$
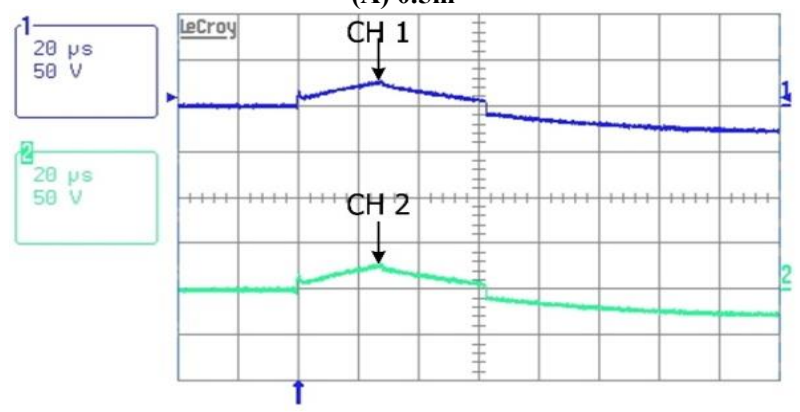

$\begin{array}{ll}\operatorname{maximum}(1) & 28.1 \mathrm{~V} \\ \operatorname{maximum}(2) & 28.1 \mathrm{~V}\end{array}$

(B) $3 \mathrm{~m}$
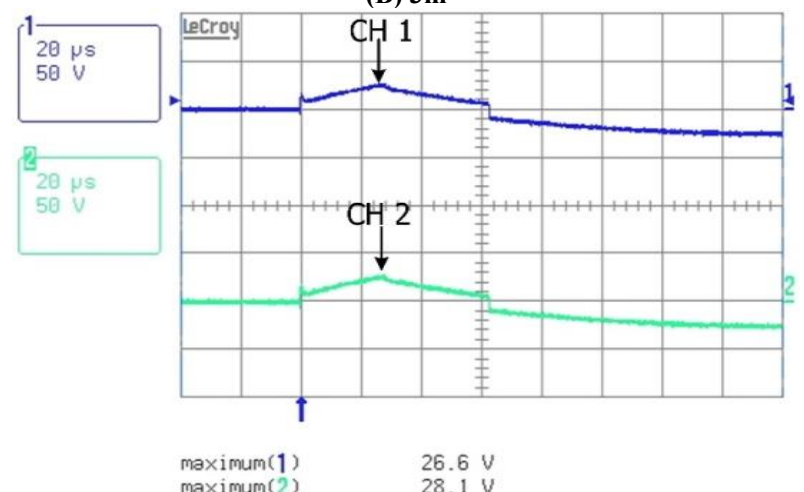

(C) $5 \mathrm{~m}$
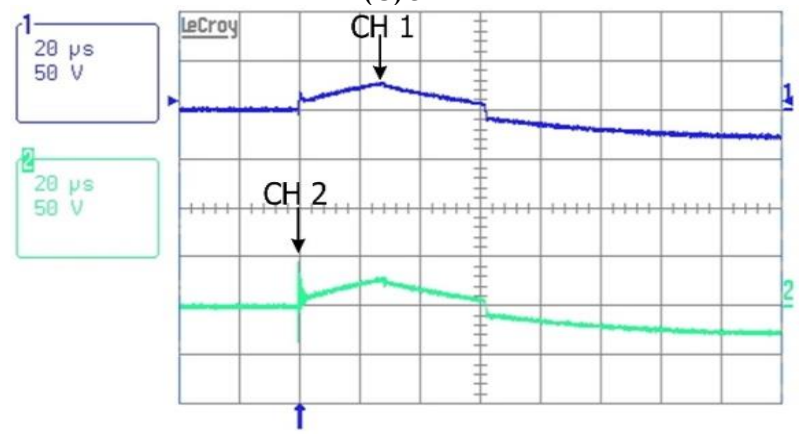

$\begin{array}{ll}\operatorname{maximum}(1) & 28.1 \mathrm{~V} \\ \text { maximum(2) } & 45.3 \mathrm{~V}\end{array}$ 
(D) $10 \mathrm{~m}$

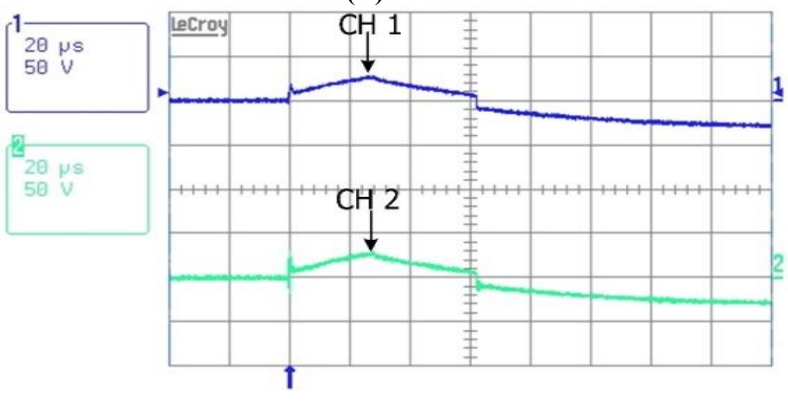

$\operatorname{maximum}(1) \quad 28.1 \mathrm{~V}$

(E) $20 \mathrm{~m}$
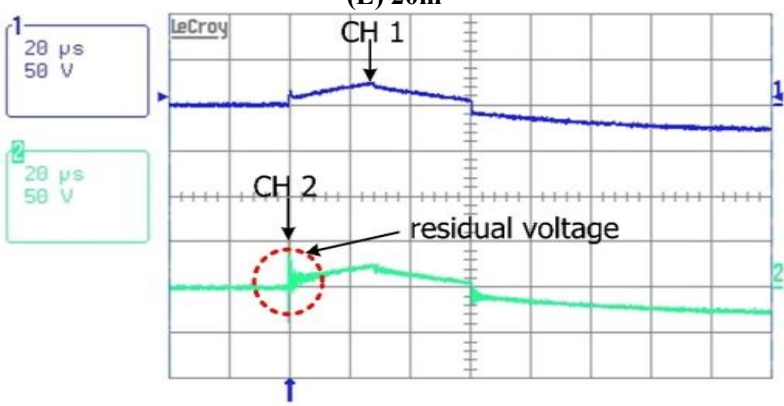

maximum(1) $25.0 \mathrm{~V}$

(F) $50 \mathrm{~m}$
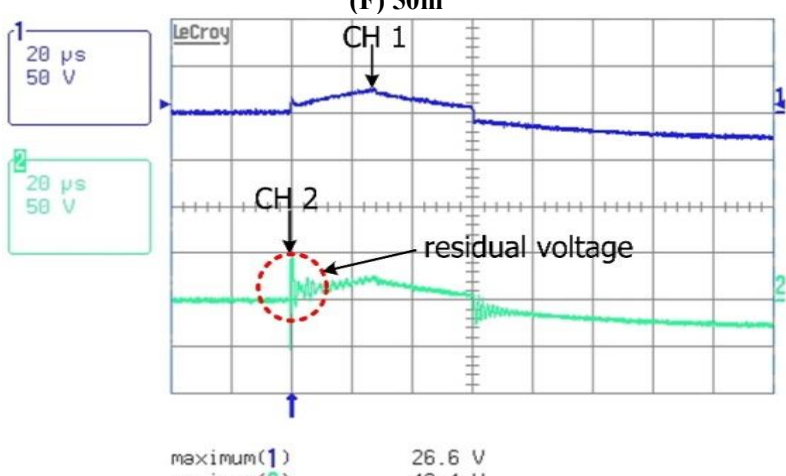

$\begin{array}{ll}\operatorname{maximum}(1) & 26.6 \mathrm{~W} \\ \operatorname{maximum}(2) & 48.4 \mathrm{~V}\end{array}$

(G) 100
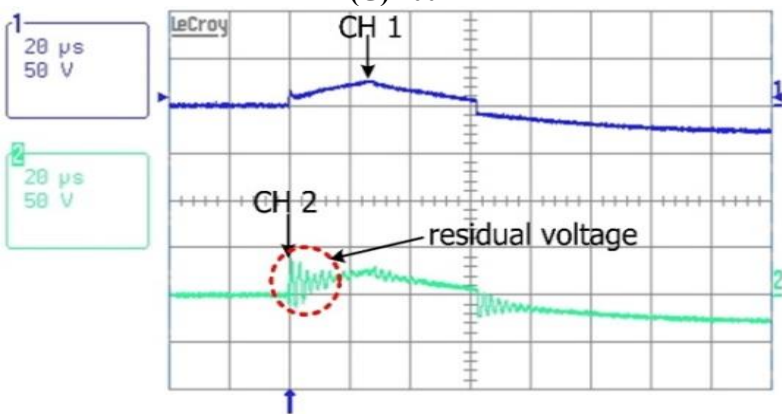

$\operatorname{maximum}(1)$
$\operatorname{maximum}(2)$$\quad 39.6 \mathrm{~V}$

Fig. 5: Experiment Results Proposed SPD Model.

\subsection{Comparison and analysis of the experiment results}

Figure 6 shows a graph comparing the measurement results of the voltage protection levels of the conventional and proposed SPD models according to the lead wire length of the SPD connection conductor. In the case of the conventional SPD model, the voltage protection level continuously rose as the lead wire length of the connecting conductors was increased to $100 \mathrm{~m}$, whereas in the case of the proposed SPD model, the voltage protection level remained below $50 \mathrm{~V}$ even if the lead wire length of the connecting conductor was increased to $100 \mathrm{~m}$. "Regulations for Surge Protector Installation for Low-Voltage Electrical Equipment" of IEC 60364-4-44 requires a $1,500 \mathrm{~V}$ or less rated impulse withstand voltage for electrical and other appliances. Considering that the voltage protection level was determined to be $1,410 \mathrm{~V}$ when the lead wire length of the connecting conductor was changed to $10 \mathrm{~m}$, the protection coordination seems to be working fine according to the length of the SPD in the case of the conventional SPD model, whereas protection coordination cannot be expected if the length exceeds $10 \mathrm{~m}$. On the other hand, the voltage protection level was determined to be $50 \mathrm{~V}$ or less in the case of the proposed SPD model even if the lead wire length of the connecting conductor was changed to $100 \mathrm{~m}$.

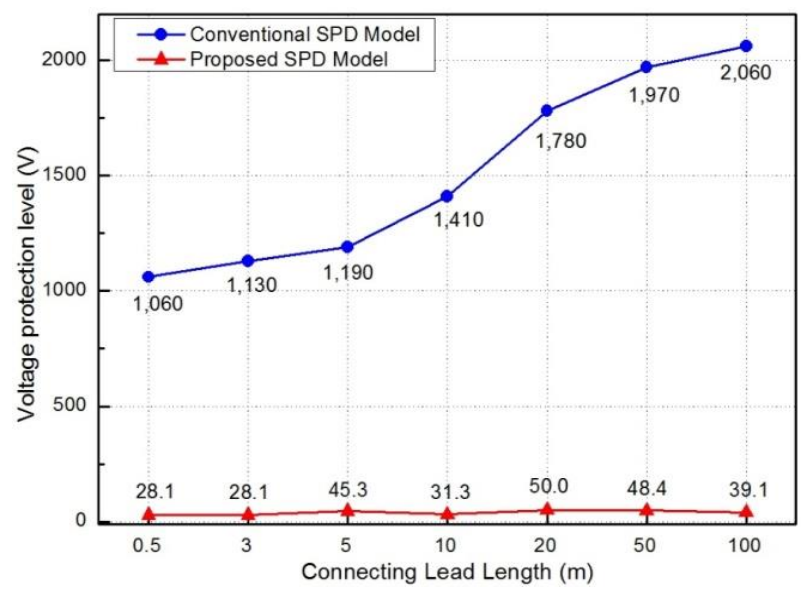

Fig. 6: Comparative Analysis of Experiment Results

\section{Conclusion}

In this study, the protection performance and coordination according to the lead wire length of the connecting conductor of the conventional and proposed surge protective device (SPD) models were verified, respectively, to assess their capability to protect equipment and devices from surges. The results showed that the protection cooperation was excellent when the lead wire length of the connecting conductor was not more than $10 \mathrm{~m}$ when the conventional SPD model was used. Meanwhile, the protection coordination was excellent even if the lead wire length of the connecting conductor was changed to $100 \mathrm{~m}$ when the proposed SPD model was used. The results of this study confirmed the superb protection performance and protection coordination of the proposed SPD model. If the proposed SPD model is applied to the primary input side of an equipment and a branch circuit requiring high stability, failure and malfunction triggered by surge shall be prevented.

\section{Acknowledgment}

This research was supported by the research fund of Hanbat National University in 2017

\section{References}

[1] Metwally, I. A., \& Heidler, F. H. (2007).Enhancement of the SPD Residual Voltage at Apparatus Terminals in Low-Voltage Power Systems. IEEE Transactions on Power Delivery, 22(4), 2207-2213. doi :10.1109/TPWRD.2007.905563.

[2] He, J. (2015).Discussions on factors influencing the effective protection distance of SPD to loads. 2015 Asia-Pacific Symposium on Elec-

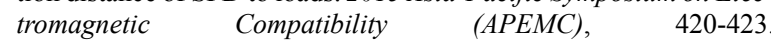
doi :10.1109/APEMC.2015.7175369.

[3] Skuletic, S., \&Radulovic, V. (2008). Effective protection distance from cascade coordinated Surge Protective Devices to equipment in low-voltage AC power circuits. 2008 43rd International Universities Power Engineering Conference (UPEC), 1-5. doi : 10.1109/UPEC.2008.4651618

[4] Amicucci, G. L., Fiamingo, F., Flisowski, Z.,Lo Piparo, G. B.,\&Mazzetti, C. (2007).Surge protective devices for low voltage 
systems: practical approach for the protection distance evaluation 2007 IEEE Lausanne Power Tech, 778-782. doi :10.1109/PCT.2007.4538414.

[5] Milardic, V., Uglesic, I., \&Pavic, I. (2010). Selection of Surge Protective Devices for Low-Voltage Systems Connected to Overhead Line. IEEE Transactions on Power Delivery, 25(3), 1530-1537. doi :10.1109/TPWRD.2010.2047410

[6] Lo Piparo, G.B., Kisielewicz, T., Mazzetti, C., \& Rousseau, A (2017). Selection procedures for surge protective devices according to the probability of damage. Electric Power Systems Research, 146 321-330. doi :10.1016/j.epsr.2017.01.038.

[7] He, Z., \& Du, Y. (2014). SPD Protection Distances to Household Appliances Connected in Parallel. IEEE Transactions on Electromagnetic Compatibility, 56(6), 1377-1385. doi :10.1109/TEMC.2014.2356400.

[8] Radulovic, V., Mujovic, S., \&Miljanic, Z. (2017). Effects of Different Combination Wave Generator Design on Surge Protective Devices Characteristics in Cascade Protection Systems. IEEE Transactions on Electromagnetic Compatibility, 59(3), 823-834. doi :10.1109/TEMC.2016.2632752.

[9] Wang, S., \&He, J. (2011). Discussion on Worst Distance between SPD and Protected Device. IEEE Transactions on Electromagnetic Compatibility, 53(4), 1081-1083. doi :10.1109/TEMC.2011.2166119.

[10] He, J., Yuan, Z., Xu, Z., Chen, S., Zou, J., \& Zeng, R. (2005). Evaluation of the effective protection distance of low-voltage SPD to equipment. IEEE Transactions on Power Delivery, 20(1), 123-130. doi :10.1109/TPWRD.2004.835254.

[11] Krasowski, D., Kisielewicz, T., Kuca, B., Flisowski, Z., Fiamingo, F., \&Mazzetti, C. (2010). On critical distance between a spd and protected appliance with respect to their voltage coordination. 201030 th International Conference on Lightning Protection (ICLP), 1-6. doi :10.1109/ICLP.2010.7845969.

[12] He, J., Yuan, Z., Wang, S., Hu, J., Chen, S., \& Zeng, R. (2010) Effective Protection Distances of Low-Voltage SPD with Different Voltage Protection Levels. IEEE Transactions on Power Delivery, 25(1), 187-195.Doi: 10.1109/TPWRD.2009.2035297.

[13] Li, C., He, J., Yu, Z., Yuan, Z., Wang, S., Hu, J., Zeng, R., \& Chen, S. (2011). Effective Protection Distances of SPDs for Household Electrical Appliances. IEEE Transactions on Electromagnetic Compatibility, 53(3), 690-699. doi :10.1109/TEMC.2011.2112368. 